* Doutoranda em Direito pela Pontifícia Universidade Católica do Rio Grande do Sul (PUC-RS). Mestre em Direito pela Universidade Federal do Rio Grande do Sul (2014), com pós-graduação em Direito Empresarial pela Fundação Getúlio Vargas (2001) e pela Escola Superior da Magistratura do Estado do Rio Grande do Sul (2002) e graduação pela UFRGS (2000). Professora no curso de Pós-Graduação em Direito e Gestão Tributária da UNISINOS. Advogada.

larissa.laks@gmail.com
LIBERDADE DE INFORMAÇÃo E

Privacidade: o Debate sobre

a CONSTitucionalidade da TRANSFERÊNCIA DO SIGILO BANCÁRIO À Administração Tributária

FREEDOM OF INFORMATION AND

Bank Secrecy: the Debate on the

CONSTITUTIONALITY OF TRANSFERRING BANK ACCOUNT INFORMATION TO THE TAX ADMINISTRATION

\section{Larissa Rodrigues Laks*}

Como citar: LAKS. Larissa Rodrigues. Liberdade de informação e privacidade: o debate sobre a constitucionalidade da transferência do sigilo bancário à administração tributária. Revista do Direito Público, Londrina, v. 12, n. 1, p.86-118, abr. 2017. DOI: 10.5433/24184-108181-1X.2017v12n1p86. ISSN: $1980-511 X$.

Resumo: O presente estudo abordará o tema do sigilo bancário, especialmente em relação à constitucionalidade da Lei Complementar $\mathrm{n}^{\mathrm{o}} 105 / 2001$, que permite o acesso direto pelo fisco, mediante a instauração de processo administrativo, à informações bancárias individuais, independentemente de autorização judicial. Nesse contexto, será considerado o debate acerca do possível conflito entre os direitos à privacidade ao sigilo de dados, 
de um lado, e de outro, o interesse público representado pela atuação da Administração Tributária, devendo a discussão também, e necessariamente, considerar as tendências relacionadas ao tema em termos de tratados internacionais assinados pelo Brasil, além das tendências existentes no direito comparado relacionadas ao tema.

Palavras-Chave: Sigilo bancário e sigilo fiscal. Privacidade e interesse público. Constitucionalidade da Lei Complementar nº5/2001. Influências do Direito Comparado.

Abstract: This research analyzes bank secrecy and its connection to the constitutionality of the supplementary law no. 105/2001, which gives tax authorities direct access to bank account information through the commencement of administrative proceedings without the need for judicial permission. Within this context, this paper explores the ongoing debate of possible conflicts of the right to privacy and bank secrecy with public interest, which is represented by tax officials. Sequentially, this paper discusses the possible tendencies related to this theme in international treaties that Brazil has ratified and comparative law.

Key-Words: Bank secrecy and fiscal secrecy. Privacy and public interest. Constitutionality of the Supplementary Law n ${ }^{\circ} 105 / 2001$. Influences of Comparative Law. 


\section{INTRODUÇÃO}

O presente estudo pretende discutir a constitucionalidade das previsões contidas na Lei Complementar $n^{\circ}$ 105/2001 (BANCO CENTRAL DO BRASIL, 2001) relacionadas à possibilidade de que o fisco, mediante processo administrativo instaurado, acesse informações bancárias de indivíduos ou empresas, sem necessidade de intervenção judicial, com a ressalva de que os dados eventualmente obtidos sejam conservados também de forma sigilosa pela administração tributária.

A discussão abrange a polêmica relacionada à possível quebra de sigilo bancário representada por tal mecanismo e suas relações com possíveis prejuízos aos direitos constitucionalmente assegurados de preservação da privacidade, de intimidade e de sigilo de dados.

O debate também compreende a reflexão acerca da eventual colisão entre princípios constitucionais: de um lado os direitos à intimidade e privacidade de outro, o do interesse público, do acesso à informação, e da eficiência na atividade administrativa.

Evidencia-se a relevância e atualidade da discussão porque o tema integra a pauta de discussão de inúmeros países e organizações internacionais, voltadas ao combate à evasão tributária, ao crime organizado e à lavagem de dinheiro em nível internacional, processos estes facilitados pela globalização e pela facilidade de circulação de capitais e de pessoas. Pretende-se abordar, também a relação entre a premissa relativa à transparência fiscal e a atuação das nações que se considerem efetivamente democráticas.

A temática do presente artigo também se mostra relevante porque, no Brasil, a discussão relativa à constitucionalidade da Lei 
Complementar $\mathrm{n}^{\circ} 105 / 2001$, relativamente à possibilidade de acesso direto aos dados bancários pela administração tributária teve sua repercussão geral reconhecida pelo Supremo Tribunal Federal em 2009. Contudo, em que pese o tempo transcorrido desde o reconhecimento da repercussão geral do tema, o julgamento do caso ainda não foi iniciado, fator gerador de instabilidade e insegurança jurídica em relação à atuação fiscal em inúmeros processo administrativos.

Assim, o estudo pretende traçar um panorama relacionando a discussão constitucional que o tema compreende, assim como trasnconstitucional, no sentido de que o combate à evasão de divisas, na atualidade é um problema que abrange inúmeros, senão a totalidade dos ordenamentos jurídicos nacionais e supranacionais.

\section{O POSSÍVEL CONFLITO ENTRE O ACESSO AOS DADOS BANCÁRIOS PELO FISCO E O DIREITO CONSTITUCIONAL À PRIVACIDADE}

O debate acerca do tema dos sigilos bancário e fiscal, como corolários do direito à liberdade de informação e de sua necessária interface com o princípio constitucional da privacidade tem ganhado espaço crescente na atualidade. Esta necessidade decorre do aumento da preocupação, por parte das sociedades e de suas instituições, relativamente ao combate à evasão fiscal, à lavagem de dinheiro e às possibilidades de ocultação de valores oriundos de práticas ilícitas, sob o manto do alegado sigilo bancário.

A questão do sigilo bancário sofre influência do sigilo fiscal, embora se tratem de problemas distintos, mas cuja análise não pode deixar de considerar o crescente relacionamento e intercâmbio entre os institutos 
e figuras. A principal distinção entre os conceitos deve referir que o sigilo bancário, em essência, protege o cidadão relativamente à divulgação de seus dados em poder de instituições financeiras públicas ou privadas, ao passo que o sigilo fiscal ampara o contribuinte relativamente ao risco de divulgação de sua situação econômica por parte de funcionários do fisco (TORRES, 2015, p. 127).

Quando se questiona sobre a possibilidade de eventual violação ao sigilo bancário, entram em oposição dois princípios: o da exclusividade, que domina a privacidade, e o da transparência, que rege a esfera pública.

O princípio da exclusividade garante a proteção dos dados do indivíduo perante qualquer outro que possa ter interesses marcados pela parcialidade, e garante, portanto, a liberdade de omitir informação. Já o princípio da transparência rege as relações públicas e determina que os processos administrativos, por envolverem assuntos de interesse público, devam ser transparentes, ressalvado o sigilo legal, que determinaria que alguns documentos sejam protocolados em apartado, por exemplo. ${ }^{1}$

No Brasil, a possibilidade de acesso direto aos dados bancários pelo fisco, independentemente de ordem judicial, decorre da inovação trazida na disposição contida na Lei Complementar no $105 / 2001$. $^{2}$ Para

1 Nesse contexto, interessantes as ponderações de Sarlet e Molinaro (2016, p. 20), onde refere, acera do princípio da transparência, que: "Do ponto de vista do seu pólo passivo, dos destinatários, nele se incluem todas as entidades estatais (o que abrange as Autarquias, Fundações, mas também as Empresas Públicas), no sentido de uma vinculação isenta de lacunas do poder público, como, ademais, se verifica na seara dos direitos e das garantias fundamentais, mas também atores privados estarão obrigados a assegurar o desfrute desse direito sempre e quando exerçam qualquer predisposição de autoridade administrativa, realizem funções ou serviços públicos ou, ainda, operem com recursos e fundos públicos, pois toda informação em posse das entidades públicas ou daquelas entidades privadas que exerçam funções ou serviços públicos ou ainda utilizem recursos públicos devem estar submetidas ao princípio da publicidade (Art. 37 da CF/1988), mas também no dever de transparência, que blinda, em regra, qualquer ocultação de informações detidas pelo poder público, traduzindo-se também em um dever de prestações informacionais."

2 Art. 5 O Poder Executivo disciplinará, inclusive quanto à periodicidade e aos limites de valor, os critérios segundo os quais as instituições financeiras informarão à administração tributária da União, as operações financeiras efetuadas pelos usuários de seus serviços. [...] $§ 2^{\circ}$ As informações transferidas na forma do caput deste artigo 
contextualização do debate, convém referir que os arts. $5^{\circ}$ e o art. $6^{\circ}$ da LC 105/2001 preveem que os agentes fiscais da União, Estados e Municípios somente poderão examinar documentos, livros e registros de instituições financeiras, inclusive os referentes a contas de depósitos e aplicações financeiras, quando houver processo administrativo instaurado ou procedimento fiscal em curso e tais exames sejam considerados indispensáveis pela autoridade administrativa competente, além de regrar que, uma vez acessadas, estas informações transferidas pelos bancos ao fisco devam ser conservadas sob sigilo fiscal.

A discussão acerca da constitucionalidade das regras previstas nos art. $5^{\circ}$ e $6^{\circ}$ da Lei Complementar $n^{\circ} 105 / 2001$ abrange o eventual conflito com as disposições relativas à proteção da intimidade que estariam consolidadas no art. $5^{\circ}$, X, XII, da Constituição Federal. Aqueles que sustentam a inconstitucionalidade do acesso direto pelo fisco aos dados bancários via de regra referem que tais possibilidades representariam afrontas aos princípios constitucionais da privacidade, da intimidade e do sigilo de dados.

O fundamento da proteção constitucional à privacidade seria,

restringir-se-ão a informes relacionados com a identificação dos titulares das operações e os montantes globais mensalmente movimentados, vedada a inserção de qualquer elemento que permita identificar a sua origem ou a natureza dos gastos a partir deles efetuados. $\S 3$ 음 Não se incluem entre as informações de que trata este artigo as operações financeiras efetuadas pelas administrações direta e indireta da União, dos Estados, do Distrito Federal e dos Municípios. \& 4 Recebidas as informações de que trata este artigo, se detectados indícios de falhas, incorreções ou omissões, ou de cometimento de ilícito fiscal, a autoridade interessada poderá requisitar as informações e os documentos de que necessitar, bem como realizar fiscalização ou auditoria para a adequada apuração dos fatos. $\S 5$ o As informações a que refere este artigo serão conservadas sob sigilo fiscal, na forma da legislação em vigor. Art. 6- As autoridades e os agentes fiscais tributários da União, dos Estados, do Distrito Federal e dos Municípios somente poderão examinar documentos, livros e registros de instituições financeiras, inclusive os referentes a contas de depósitos e aplicações financeiras, quando houver processo administrativo instaurado ou procedimento fiscal em curso e tais exames sejam considerados indispensáveis pela autoridade administrativa competente. Parágrafo único. O resultado dos exames, as informações e os documentos a que se refere este artigo serão conservados em sigilo, observada a legislação tributária (BANCO CENTRAL DO BRASIL, 2001). 
portanto, a limitação da esfera de vida íntima da pessoa em relação à curiosidade indevida de terceiros, uma vez que a privacidade não protegeria posses, propriedades, mas relações de confiança, estratégicas, ou de proteção do foro íntimo contra a curiosidade indevida. A proteção à privacidade também se relaciona à liberdade individual, no sentido de que informações relacionadas à intimidade da pessoa não sejam expostas ao público, e sim mantidas na esfera de sua vida íntima. (FERRAZ JÚNIOR, 2015, p. 98).

A previsão constitucional da intimidade, da vida privada, da correspondência e de dados pessoais está descrita no art. $5^{\circ}$, incisos $\mathrm{X} \mathrm{e}$ XII, pelos quais:

Art. $5^{\circ}$ Todos são iguais perante a lei, sem distinção de qualquer natureza, garantindo-se aos brasileiros e aos estrangeiros residentes no País a inviolabilidade do direito à vida, à liberdade, à igualdade, à segurança e à propriedade, nos termos seguintes:

$[\ldots]$

X - são invioláveis a intimidade, a vida privada, a honra e a imagem das pessoas, assegurado o direito a indenização pelo dano material ou moral decorrente de sua violação; $[\ldots]$

XII - é inviolável o sigilo da correspondência e das comunicações telegráficas, de dados e das comunicações telefônicas, salvo, no último caso, por ordem judicial, nas hipóteses e na forma que a lei estabelecer para fins de investigação criminal ou instrução processual penal;

Da leitura do $\operatorname{art} .5^{\circ}$, caput, em conjunto com as disposições contidas nos incisos X e XII, é possível constatar que o eventual impedimento de acesso pela administração a dados bancários implica a eventual possibilidade de ocultação de provas, que constituem mecanismos para a aplicação da lei, o que sujeitaria a concretização da 
aplicação da lei tributária a subjetivismos indesejáveis. (SANTI, 2015, p. 575).

A argumentação supratranscrita leva necessariamente à reflexão acerca da eventual colisão entre princípios constitucionais: de um lado os direitos à intimidade e privacidade de outro, o acesso à informação, a eficiência na atividade administrativa e o interesse público, além da determinação consagrada no art.145, $\S 1^{\circ}$, da Constituição Federal no sentido de que, sempre que possível, os impostos devam ter caráter pessoal e ser graduados segundo a capacidade econômica do contribuinte, facultando-se à administração tributária, para conferir efetividade a esses objetivos, identificar, respeitados os direitos individuais e nos termos da lei, o patrimônio, os rendimentos e as atividades econômicas do contribuinte.

Contudo, talvez previamente à discussão sobre a eventual necessidade de sopesamento de princípios constitucionais colidentes, a discussão deva centrar-se na questão relativa à discussão de ser o sigilo bancário expressão dos direitos à privacidade e intimidade, sobretudo quando a própria Lei Complementar $n^{\circ} 105 / 2001$ já prevê que, nas hipóteses em que o fisco acesse os referidos dados, devam estes ser conservados sob estrito sigilo.

Desta forma, as disposições contidas na Lei Complementar $\mathrm{n}^{\circ}$ 105/2001, em realidade não preveriam a quebra de sigilo, mas sim, aquilo que devemos denominar como transferência de sigilo bancário para sigilo fiscal. Assim, em observância às disposições contidas na lei em questão, as informações somente seriam acessadas na hipótese de instauração de procedimento administrativo regular, quando não possam ser acessadas por outro meio, devendo as referidas informações ser mantidas sob sigilo, constituindo crime a sua violação. 
Portanto, uma vez considerado que o fisco tenha o dever legal de manter as informações a que tenha acesso sob sigilo, e que em realidade este processo caracterizaria a transferência do sigilo bancário para o fisco, ficaria demonstrado o exagero quando se invoca a questão da violação ao direito à privacidade e intimidade a partir do acesso às informações bancárias pela administração fiscal. ${ }^{3}$

A discussão também abarca a temática do conteúdo da determinação contida no $\operatorname{art} .5^{\circ}$, XII, relativa à "inviolabilidade da comunicação de dados", invocada também como razão para aqueles que pretendem sustentar que o acesso pelo fisco aos dados bancários violaria a disposição constitucional.

Observe-se, em primeiro lugar, que a própria construção semântica da determinação constitucional faz referência à inviolabilidade da comunicação de dados, o que levaria à interpretação de que o que se pretende proteger é o mecanismo, o processo de comunicação de dados, o qual não poderia ser interceptado, e não os dados em si. (SANTI, 2015, p. 580).

Outro ponto importante que reforçaria a interpretação no sentido de que a constituição, em realidade, não protege o alegado sigilo bancário em relação ao fisco, decorreria da interpretação sistemática da disposição contida nos arts. $5^{\circ}$, incisos X e XII, em conjunto com o art.145, parágrafo único, da Constituição Federal. Segundo este último artigo, os impostos devem, quando possível, ter caráter pessoal e ser graduados segundo a capacidade econômica do contribuinte, facultando-se à administração

3 Nesse sentido, refere Rocha (2003, p. 30): “A vida econômica dos particulares não parece ser parcela de seu íntimo, ou não compõe a intimidade da pessoa tutelada constitucionalmente. E exato que qualquer informação que não diga respeito ao público é privado, logo, não pode ser exposta sem o prévio, voluntário e autorizado conhecimento do interessado. Mas o interesse público não pode ficar em desvalia diante do capricho do particular que se negue a dar a conhecer à pessoa estatal o que nada tem de secreto ou de oculto ou clandestino ao interesse ilegítimo do público." 
tributária, para conferir efetividade a esses objetivos, identificar, respeitados os direitos individuais e nos termos da lei, o patrimônio, os rendimentos e as atividades econômicas do contribuinte.

Assim a atribuição conferida constitucionalmente à administração fiscal, de identificar, nos termos da lei, o patrimônio, rendimentos e atividade econômicas do contribuinte estaria em perfeita consonância com a possibilidade, e inclusive, com a necessidade de que o fisco, para o bom desempenho de tais funções, possa ter acesso direto aos dados bancários, através de procedimento administrativo regular, independentemente de autorização judicial.

Por fim, ainda que fossem desconsiderados todos os argumentos antes referidos, no sentido da constitucionalidade das disposições contidas nos arts. $5^{\circ}$ e $6^{\circ}$ da Lei Complementar $n^{\circ} 105 / 2001$, sendo identificada uma colisão entre os princípios constitucionais, o entendimento mais prudente indica que devesse preponderar o interesse público, expresso pela possibilidade de realização da já referida transferência de sigilo bancário ao fisco.

Isso se explica, primeiramente, porque quando entram em jogo questões que envolvem a quebra de sigilo bancário, haveria uma tendência de que se privilegie o princípio da transparência. Isso decorreria do entendimento no sentido de que, nesses casos, haveria um interesse público que fundamentaria a primazia do princípio da transparência, em detrimento do princípio da exclusividade das informações pessoais, ou da privacidade (FERRAZ JUNIOR, 2015, p. 103).

Nesse contexto, a questão poderia ser resolvida através de um juízo de ponderação entre princípios ${ }^{4}$, através de uma avaliação relativa à

4 Para melhor compreensão da das possibilidades de ponderação entre princípios constitucionais, vide, por todos Alexy (2008, p. 93). 
adequação, proporcionalidade e necessidade da relativização da proteção da intimidade que porventura exista nesses dados bancários, em cotejo com a necessidade de eficácia na atuação da administração tributária. ${ }^{5}$

Portanto, a confiabilidade dos cidadãos na atividade estatal seria um pressuposto de afirmação da democracia, que vive da confiança do povo no governo. Assim, tudo que concorra para que o Estado não possa adequadamente atuar, conspira contra a democracia. Portanto, a eventual relativização da liberdade individual expressa pela transferência do sigilo bancário ao fisco, em realidade, constituiria um mecanismo de efetividade da ação fiscalizadora, e, portanto, de fortalecimento da confiança nas instituições, expressão do fortalecimento democrático. (ROCHA, 2003, p. 40).

Além disso, conforme adiante se examinará, a questão da vedação ao sigilo bancário como empecilho à atuação fiscal constitui uma premissa inarredável colocada por diversos organismos internacionais como pressuposto a ser observado por nações efetivamente democráticas. Assim, à medida que o Brasil caminhe no sentido de ser considerado não apenas como uma jovem democracia, deve primar pela consolidação das regras que restrinjam ou impossibilitem alegações como a do sigilo bancário como óbice à atuação fiscal.

\section{A JURISPRUDENCIA DO SUPREMO TRIBUNAL}

5 Rocha (2003, p. 40) refere nesse contexto que: “A liberdade mesma depende de limites. O sigilo fiscal e o bancário são postos para que os direitos fundamentais à privacidade sejam resguardados até o limite que o interesse de todos esteja em causa e determine as condutas administrativas necessárias, no perfeito espaço da juridicidade e da legalidade. Mas as atividades econômicas das pessoas e contas bancárias não são as novas cavernas fechadas de modo absoluto a assegurar a intangibilidade dos novos Ali Babás. Constituição existe como garantia de direitos, não como gaiola de falcatruas. No sistema constitucional justo- e que, portanto, vislumbra e cuida de todos e não de alguns dos cidadãos - até a liberdade precisa de limites. Os sigilos fiscal e bancário podem ser cogitados como instrumentos limitadores ao exercício de direitos, mas, se juridicizados segundo os princípios da justiça, honestidade e eficácia devida pelo Estado, não há como se considerar agressão, mas composição daqueles." 


\section{FEDERAL ACERCA DA CONSTITUCIONALIDADE DA LEI COMPLEMENTAR N 105/ 2001.}

É necessário que se refira que as hipóteses de quebra de sigilo bancário permitidas ao fisco são duas: a primeira, descrita no art. 197, II do $\mathrm{CTN}^{6}$ e a segunda, no arts. $5^{\circ}$ e $6^{\circ}$ da Lei Complementar $\mathrm{n}^{\circ}$ 105/01. Diversos são os entendimentos a sustentar que ambas as possibilidades encontram respaldo no disposto no art. $145 \mathrm{da} \mathrm{CF}$, que daria guarida à quebra de sigilo bancário perpetrada pelo fisco. Outras posições, contudo, entendem que as hipóteses de quebra de sigilo só possam ser determinadas pelo judiciário ou, quando muito, através de Comissões Parlamentares de Inquérito do Congresso Nacional, com respaldo no art. $58 \S 3^{\circ}$ da Constituição Federal ${ }^{7}$.

A questão relativa à constitucionalidade da Lei Complementar $\mathrm{n}^{\mathrm{o}} 105 / 2001$, no que pertine à possibilidade de acesso direito pelo fisco às informações e movimentações bancárias vêm sendo objeto de inúmeras discussões no Supremo Tribunal Federal, sem que a matéria tenha ainda sido definitivamente decidida.

$\mathrm{O}$ assunto foi inicialmente discutido na $\mathrm{AC} \mathrm{n}^{\circ} 33$ (BRASIL, 2010a) e no RE 389.808 (BRASIL, 2010b), assim como nas Ações Diretas de Inconstitucionalidade n ${ }^{\circ} 2390,2397$ e 2859 (BRASIL, 2015),

6 Art. 197. Mediante intimação escrita, são obrigados a prestar à autoridade administrativa todas as informações de que disponham com relação aos bens, negócios ou atividades de terceiros: II - os bancos, casas bancárias, Caixas Econômicas e demais instituições financeiras (BRASIL, 1966).

7 Art. 58. O Congresso Nacional e suas Casas terão comissões permanentes e temporárias, constituídas na forma e com as atribuições previstas no respectivo regimento ou no ato de que resultar sua criação. $\S$ $3^{\circ}$ As comissões parlamentares de inquérito, que terão poderes de investigação próprios das autoridades judiciais, além de outros previstos nos regimentos das respectivas Casas, serão criadas pela Câmara dos Deputados e pelo Senado Federal, em conjunto ou separadamente, mediante requerimento de um terço de seus membros, para a apuração de fato determinado e por prazo certo, sendo suas conclusões, se for o caso, encaminhadas ao Ministério Público, para que promova a responsabilidade civil ou criminal dos infratores. Acerca do tema, vide julgamento (BRASIL, 1988). 
todas apensadas sob relatoria do Ministro Dias Toffoli e ainda pendentes de julgamento. As Ações Diretas de Inconstitucionalidade em questão discutem a constitucionalidade da possibilidade de acesso às informações bancárias diretamente pela fiscalização tributária, nos termos previstos na Lei Complementar no 105/2001.

O tema teve sua repercussão geral reconhecida em 2009, no Recurso Extraordinário $\mathrm{n}^{\mathrm{o}} 601.314 / \mathrm{SP}^{8}$, o qual, em que pese o tempo transcorrido desde o reconhecimento da referida repercussão geral, ainda não teve seu julgamento iniciado. A situação de prolongada indefinição deste caso cria uma situação de profunda insegurança jurídica, a depender da solução adotada no julgamento deste processo, que pode colocar sob suspeita ou anular inúmeros processos administrativos em que o fisco acessou dados bancários sem prévia autorização judicial

Acaso considerada lícita e constitucionalmente autorizada a quebra de sigilo bancário por parte do fisco, convém reiterar o entendimento já exposto, no sentido de que o sigilo não seria propriamente quebrado, mas transferido ao fisco, que também tem o dever legal de manter em sigilo as informações eventualmente obtidas.

Além disso, nos processos administrativos, embora prevista constitucionalmente a aplicação do princípio da publicidade, há que se observar que devam ser respeitadas as disposições da Lei 8.884/94, que rege o processo administrativo de competência dos órgãos de defesa da concorrência e determina o respeito ao sigilo legal na requisição de

8 RE 601314/SP - Repercussão geral no Recurso Extraordinário. Relator Min Ricardo Lewandowski, julgamento em 22/10/2009, publicado em 20/11/2009, cuja ementa refere que: CONSTITUCIONAL. SIGILO BANCÁRIO. FORNECIMENTO DE INFORMAÇÕ̃ES SOBRE MOVIMENTAÇÃO BANCÁRIA DE CONTRIBUINTES, PELAS INSTITUIÇÕES FINANCEIRAS, DIRETAMENTE AO FISCO, SEM PRÉVIA AUTORIZAÇÃO JUDICIAL (LEI COMPLEMENTAR 105/2001). POSSIBILIDADE DE APLICAÇÃO DA LEI 10.174/2001 PARAAPURAÇÃO DE CRÉDITOS TRIBUTÁRIOS REFERENTES A EXERCÍCIOS ANTERIORES AO DE SUA VIGÊNCIA. RELEVÂNCIA JURÍDICA DA QUESTÃO CONSTITUCIONAL. EXISTÊNCIA DE REPERCUSSÃO GERAL. (BRASIL, 2009). 
documentos e informações (art. $7^{\circ}$.inc.IX, 14,II). Isso se deve ao fato de que, embora uma empresa possa ter informações sigilosas averiguadas pelo fisco, tais informações não podem, contudo, vir a público e prejudicar sobremaneira suas atividades num ambiente concorrencial. (FERRAZ JUNIOR, 2015, p. 103).

Nas últimas décadas, também palpitaram no Brasil inúmeras discussões doutrinárias e jurisprudenciais acerca da possibilidade de quebra de sigilo bancário pelo Ministério Público.

Aqueles que que advogam no sentido da inconstitucionalidade da Lei Complementar $n^{\circ} 105 / 2001$, sustentam que, assim como o Ministério Público, ao fisco faltaria imparcialidade, dada a sua condição de parte interessada na cobrança de tributos, e por tal razão, seu acesso aos dados protegidos pelo sigilo bancário deveria necessariamente depender de autorização judicial. ${ }^{9}$

A posição que sustenta a prescindibilidade de intervenção judicial para o acesso de dados pelo fisco, refere que a preservação da intimidade e privacidade representadas pelo sigilo bancário deva ser ponderada em relação aos interesses de ordem pública. Referem ainda que o exercício da atividade fiscal representa uma ferramenta eficiente de combate à evasão fiscal. Além disso, segundo os defensores desta posição, o eventual temor de que possam ser praticados abusos por agentes públicos no acesso aos sigilos bancários e fiscal de forma indevida não poderia ser obstáculo para a atuação da administração tributária, inclusive porque a vida econômica dos particulares não poderia ser considerada exatamente uma parcela do seu íntimo.

Assim, equivocado seria o entendimento no sentido de que a

9 Dentre os Ministros do Supremo Tribunal Federal que já votaram no sentido de que a solicitação de informações bancárias por parte do fisco dependa de ordem judicial, destacam-se os Ministros Marco Aurélio, Ricardo Lewandowski, Cesar Peluso, Gilmar Mendes e Celso de Mello. 
preservação de dados fiscais seja corolário da preservação da vida íntima da pessoa e de seu direito à privacidade. A intimidade, portanto, diria respeito àquilo que se refere ao espaço mais resguardado da privacidade, àquilo que a pessoa reserva somente para si ou para aqueles que lhe são muito íntimos, que diz respeito à individualidade pessoal (ROCHA, 2003, p. 30), sendo que a movimentação bancária, sob tal prisma, não poderia ser considerada parcela do íntimo pessoal protegido constitucionalmente.

Outros argumentos a sustentar a desnecessidade de intervenção judicial para o acesso às informações bancárias pela administração tributária o fazem referindo que, em realidade, não haveria quebra de sigilo, mas sim transferência de sigilo. A transferência de sigilo se respaldaria nas regras contidas no art. 198, Parágrafo único, do Código Tributário Nacional, assim como no $\S 5^{\circ}$ do art. $5^{\circ}$ e parágrafo único do art. $6^{\circ}$ da LC 105/2001, que dispõem que, uma vez recebidas pela Administração Tributária os dados e informações sigilosas fornecidos pelo banco, esta teria o dever legal de mantê-los conservados sob sigilo fiscal. Assim, a manutenção destas informações sob sigilo fiscal não caracterizaria sob nenhum aspecto a divulgação dos dados a terceiros ou a exposição da pessoa a quem as informações se refiram (CAMBI; POMPILIO, 2014, p. 101).

Relativamente ao argumento no sentido da parcialidade dos interesses do fisco quando acessa as informações bancárias sob sigilo, observam-se entendimentos no sentido de que a atuação fiscal seria marcada pelos princípios da moralidade, impessoalidade, eficiência e legalidade, o que retiraria o caráter arbitrário da atuação da administração tributária. ${ }^{10}$

10 Vide voto da Ministra Ellen Gracie no julgamento da AC 33/PR, Tribunal Pleno, Rel. Min Marco Aurélio, julgamento em 24.11.2010, publicado em 10-02-2011, (BRASIL, 2010a), onde refere que: "Se de um lado, a atividade tributária visa à eficiência arrecadatória, de outro, deve obediência aos princípios que 
Portanto, em realidade, os sigilos bancários e fiscal devem ser relacionados ao direito da pessoa de não ver expostos a público, ou a pessoas estranhas àquelas que têm acesso aos dados bancários em virtude da atividade fiscalizadora, relativamente ao seus rendimentos, bens e movimentações financeiras (ROCHA, 2003, p. 30).

Nesse contexto, mesmo aqueles que advogam no sentido da possibilidade e constitucionalidade de acesso destes dados pelo fisco devem reconhecer que tal acesso demande cautela e uma atuação responsável, devendo ser punidas as atividades da fiscalização que extrapolem os limites legais, conforme previsão contida nas regras anteriormente referidas, que criminalizam a atividade fiscalizadora exercida de forma irresponsável. Esta necessidade se impõe na sociedade contemporânea, tendo em vista que a exploração ilegítima ou ilícita de dados relacionados ao sigilo fiscal pode dar espaço a notícias caluniosas, crimes, sequestros, prejuízos à atividade negocial, entre tantos outras consequências extremamente danosas.

Contudo, o entendimento que se considera como mais adequado e correto no presente estudo é o de que o direito à eficiência na fiscalização e à transparência fiscal deva prevalecer, pois não seria o impedimento às ações administrativas e à ação estatal que poderá permitir a construção de uma atuação estatal confiável e eficiente.

Preponderaria, portanto, o interesse relativo ao combate à corrupção e à evasão de divisas, devendo os direitos ao sigilo bancário e fiscal ser observados até o limite em que o interesse público de todos

inspiram toda a Administração Pública, como a legalidade, a impessoalidade e a moralidade (art. 37 da Constituição). A eficiência visa à arrecadação de tudo o que efetivamente for devido em conformidade com a lei, mas nada mais (art.150, I da Constituição). Relembre-se que o tributo é cobrado em atividade administrativa plenamente vinculada (art. $3^{\circ} \mathrm{CTN}$ ). Não há que se dizer, pois, que o poder de polícia fiscal não seja orientado à adequada aplicação da lei." 
seja a causa determinante de seu exepcionamento. ${ }^{11}$

\section{O TEMA DO SIGILO BANCÁRIO E FISCAL NO DIREITO COMPARADO E OS ACORDOS INTERNACIONAIS PARA EVITAR A BITRIBUTAÇÃO E PARA A TrOCA DE INFORMAÇÕES EM MATÉRIA TRIBUTÁRIA}

A globalização traz consigo um processo irreversível de internacionalização de mercados, de movimentação de capitais e pessoas (GODOY, 2015, p. 368), e de facilidades de realização de aplicações financeiras por empresas ou pessoas em bancos de qualquer país do mundo. Esse fenômeno de internacionalização de bancas traz consigo, contudo, uma crescente facilidade para a prática de ilícitos fiscais.

A tendência atualmente verificada internacionalmente, no sentido do aumento do rigor e controle no combate à evasão fiscal, assim como a crescente proliferação de acordos internacionais ou multilaterais para a cooperação no combate à fraude fiscal, podem representar indicativos do surgimento de uma nova ordem jurídica global, denominada por Marcelo Neves de "transconstitucionalismo", quando refere que:

Contra essas tendências, o transconstitucionalismo implica o reconhecimento de que as diversas ordens jurídicas entrelaçadas na solução de um problema-caso - a saber, de direitos fundamentais ou humanos e de organização

11 Nesse contexto, muito pertinentes as palavras de Antunes (2003, p. 40), ao referir que: "A democracia, sabe-se, vive da confiança do povo no governo. Corrupção, vantagens de uns sobre outros, privatização da coisa pública, enfim, tudo o que concorra para que o Estado não possa atuar e, não podendo, conduza à desconfiança ou à não confiança do cidadão na pessoa estatal, nos governos e na administração pública nele atuante é uma fresta oferecida ao enfraquecimento do Estado e ao aumento às mazelas sociais sem atuação eficaz do Direito e seus instrumentos. A liberdade mesma depende de limites. O sigilo fiscal e o bancário são postos para que os direitos fundamentais à privacidade sejam resguardados até o limite que o interesse de todos esteja em causa e determine as condutas administrativas necessárias, no perfeito espaço da juridicidade e da legalidade. Mas as atividades econômicas das pessoas e contas bancárias não são as novas cavernas fechadas de modo absoluto a assegurar a intangibilidade dos novos Ali Babás." 
legítima de poder - que lhes são concomitantemente relevantes, devem buscar formas transversais de articulação para a solução do problema, cada uma delas observando a outra, para compreender os seus próprios limites e possibilidades de contribuir para solucioná-lo. (NEVES, 2013, p. 297).

Para o autor, portanto, o Estado nacional deixaria de ser o único espaço para a solução de problemas, passando a caracterizar-se apenas como uma das alternativas de solução de impasses jurídicos, uma vez que a integração sistêmica da sociedade mundial, em nível cada vez maior, levaria à uma espécie de desterritorizalização ou emancipação das controvérsias em relação à uma única ordem jurídica (NEVES, 2013).

Desta forma, estaria caracterizada a necessidade de que sejam tomadas ações conjuntas entre países, assim como relativamente ao aumento da transparência em matéria fiscal, que muitas vezes é contraposta por alegações relacionadas à alegada quebra do sigilo bancário, o que também se verifica no Brasil, país que ainda discute a constitucionalidade da possibilidade de acesso direito à informações bancárias pelo fisco, prevista nos arts. $5^{\circ}$ e $6^{\circ}$ da Lei Complementar $n^{\circ}$ $105 / 2001$.

Contudo, a despeito dos argumentos no sentido da preocupação com a manutenção do sigilo fiscal, e sua relação com a privacidade, o que se verifica, em realidade, é que a manutenção do argumento relacionado à proteção exacerbada do sigilo bancário não se mostra compatível com os pressupostos estabelecidos pelas democracias atualmente consideradas como mais desenvolvidas.

A crescente necessidade de transparência em matéria fiscal seria considerada, assim, como um pressuposto democrático, no sentido da proteção do interesse de todas as administrações tributárias, voltadas ao 
combate de ilícitos. Desta forma, o argumento relativo à preservação do sigilo bancário não poderia preponderar frente ao interesse público, até mesmo porque, tanto a legislação pátria como os tratados internacionais que permitem a transferência do sigilo bancário às administrações fiscais, necessariamente fazem constar de seus regramentos rígidas disposições relacionadas à manutenção deste sigilo fiscal. (VALADÃO, 2015, p. 407).

Verifica-se, portanto, em nível mundial, uma crescente preocupação para que as nações desenvolvam mecanismos de cooperação no sentido da troca de informações e de assistência para a cobrança de impostos, assim como a tendência no sentido de que as nações devam desenvolver esforços conjuntos para o combate ao crime organizado, à lavagem de dinheiro e à evasão de divisas. ${ }^{12}$ A preocupação com a potencial perda de receitas, e a necessidade de cooperação internacional para o intercâmbio de informações fiscais entre países também vem sendo uma prioridade para organismos internacionais como a OCDEOrganização para Cooperação e Desenvolvimento Econômico e para a ONU- Organização das Nações Unidas.

$\mathrm{O}$ art. 26 da Convenção Modelo para a tributação de Renda e Capital, da Organização para a Cooperação e Desenvolvimento Econômico - OCDE, ao dispor sobre a troca de informações entre autoridades competentes, refere expressamente em seu inciso $\mathrm{V}$ (OECD, 2008, p. 17), que não são admissíveis eventuais exceções à obrigatoriedade de troca de informações com o objetivo de se negar o envio de dados em decorrência do sigilo bancário (GODOY, 2015, p. 366). Além disso, a Convenção da Organização das Nações Unidas

12 Valadão $(2015$, p. 383), refere nesse contexto que: “A troca internacional de informações em matéria tributária constitui um dos núcleos essenciais para a detecção de práticas evasivas e elisivas, ou elusivas (a depender da terminologia empregada), nos tempos atuais de economias interpenetradas e interdependentes em que quase todos os empreendimentos importantes têm operações transnacionais ou são empreendimentos transnacionais." 
(UNITED NATIONS, 2001, p. 43-44) relativa ao tema reproduz redação idêntica, no que pertine à troca de informações, à adotada pela OCDE. ${ }^{13}$ Além do papel desempenhado por organismos como a OCDE e a ONU, convêm referir que o grupo de países denominado G-20, grupo composto pelas vinte maiores economias mundiais, do qual o Brasil faz parte, estaria também intensificando suas preocupações e ações no sentido do combate à corrupção, à evasão de divisas e à lavagem de dinheiro, o que se intensificou desde a eclosão da crise financeira mundial, em 2007. Assim, na Cúpula de Londres, de abril de 2009, o G-20 estabeleceu como prioridade a troca de informações tributárias, excluindo expressamente qualquer tipo de hipótese de favorecimento ao sigilo bancário (VALADÃO, 2015, p. 397).

Este ambiente global propício à troca de informações entre nações também ficaria evidenciado em decorrência da realização e dos resultados do Fórum Global da Transparência (VALADÃO, 2015), evento criado pela $\mathrm{OCDE}$, mas que conta com a participação de diversos países não associados à organização, a exemplo do Brasil, que aderiu ao evento em setembro de 2009, na edição realizada no México (VALADÃO, 2015, p. 397).

Atualmente, portanto, o Fórum Global da Transparência elegeu alguns standarts para que as nações possam ser consideradas como pertencentes ao grupo daquelas que colaboram com a transparência em matéria fiscal, e dentre os pré-requisitos para a qualificação como nação cooperativa estão existência de 12 tratados que contenham as cláusulas

13 OCDE (2015). Segundo a versão em português cláusula 26 em comento, inciso V: “Artigo 26. ․ Troca de informações: 5 . O disposto no número 3 não pode em caso algum ser interpretado no sentido de permitir que um Estado contratante se recuse a prestar informações apenas porque estas são detidas por uma instituição bancária, um outro estabelecimento financeiro, um mandatário ou por uma pessoa agindo na qualidade de agente ou fiduciário, ou porque essas informações são conexas com os direitos de propriedade de uma pessoa." 
padrões do art.26 do Modelo da OCDE, a tendência de que seja verificada a efetiva troca de informações entre os países signatários do acordo, assim como disposições no sentido da possibilidade dessas trocas na legislação interna de cada país (VALADÃO, 2015, p. 397).

A diretiva 77/99/CEE rege a questão da assistência mútua em matéria fiscal na União Europeia e, em função dos seus dispositivos, diversas decisões têm sido tomadas no âmbito do Tribunal de Justiça da Comunidade Europeia. Nesse contexto, é possível destacar a posição tomada no processo C-255/02 (caso Halyfax), que, ao decidir sobre a questão da obtenção de incentivos fiscais, referiu que um dos objetivos da Sexta Diretiva é a luta contra a prática de fraudes, referindo, contudo, que este objetivo deva ser ponderado para que os Estados-Membros não extrapolem o necessário para atingir tal objetivo ${ }^{14}$. Da mesma forma, no processo C-451-05, conhecido como "Caso Elisa" ficou registrado, através das conclusões expostas pelo Advogado-Geral J. Mazák que, nos termos da Directiva 77/799/CEE, as autoridades competentes dos Estados-Membros trocarão todas as informações que lhes permitam o estabelecimento correto dos impostos sobre o rendimento e o patrimônio. ${ }^{15}$

Além disso, no contexto transnacional que delinearia um novo cenário jurídico global, seria possível destacar os Estados Unidos da América, como nação que vem desempenhando um relevante papel de liderança no combate ao crime de sonegação fiscal, representado por exigências feitas pelo país à Suíça, notoriamente reconhecida pela exacerbada preocupação com preservação do sigilo bancário. (SANTI, 2015, p. 569). Assim, durante o governo Barack Obama, os Estados

14 Conforme Acórdão do Tribunal de Justiça da Comunidade Européia- Processo C-255/02 (Grande Seção, julgado em 21 de fevereiro de 2006. (HALIFAX, 2006).

15 Conforme conclusões do Advogado Geral J. Mazák, apresentadas em 26/04/06, apresentadas no processo do Tribunal de Justiça da Comunidade Europeia - C -451/05. (MAZÁK, 2006). 
Unidos implementaram exigências à União de Bancos Suíços, (UBS), gigantesca instituição bancária suíça, para que fornecesse nomes de 250 clientes americanos que teriam sido por ela auxiliados a fraudar o fisco, estando o descumprimento da exigência ameaçada com a punição de retirada de sua licença de operação nos EUA. Mais recentemente, o governo americano exigiu da referida instituição os nomes de 52.000 clientes americanos que seriam titulares de contas ilegais, o que gerou reações políticas na Suíça e inclusive propostas no sentido de que o sigilo bancário fosso consolidado como cláusula constitucional (SANTI, 2015, p. 569).

A relação entre o Brasil e os Estados Unidos da América relativamente à troca de informações tributárias é atualmente regida por um Acordo, promulgado através do Decreto $n^{\circ} 8.003$, de 15/05/2013, para o Intercâmbio de Informações relativas a tributos, firmado em Brasília, em 20 de março de 2007. Este Decreto traz em seu bojo disposições expressas acerca do acesso direito ${ }^{16}$ à informações a serem intercambiadas por autoridades fazendárias, assim como não contempla a possibilidade de sigilo dentre as hipóteses para o não atendimento de uma requisição feita entre um dos países. ${ }^{17}$

16 Segundo o disposto no Decreto no 8.003, de 15/05/2013, art.IV, inc..I: "autoridade competente" significa, para a República Federativa do Brasil, o Ministro da Fazenda, o Secretário da Receita Federal e para os Estados Unidos da América, o Secretário do Tesouro ou seu representante, ou seus representantes autorizados; e pelo art.V: Intercâmbio de Informações a Pedido:1. A autoridade competente da Parte requerida deverá fornecer, a pedido da Parte requerente, informações para os fins mencionados no Artigo I. Tais informações deverão ser intercambiadas independentemente de a Parte requerida delas necessitar para propósitos tributários próprios ou de a conduta sob investigação constituir crime de acordo com as leis da Parte requerida, caso ocorrida em seu território. A autoridade competente da Parte requerente deverá formular um pedido de informações com base neste Artigo apenas quando impossibilitada de obter as informações solicitadas por outros meios, exceto quando o recurso a tais meios acarretar dificuldades desproporcionais. (BRASIL, 2013).

17 Segundo o disposto no Decreto $\mathrm{n}^{\circ} 8.003$, de $15 / 05 / 2013$, não se observa a questão do sigilo bancário como possibilidade de recusa ao atendimento de um pedido. Segundo o art. VII do Decreto, portanto, somente seria possível à recusa ou negação de assistência pela parte requerida nas seguintes hipóteses: a) quando o pedido não for feito em conformidade com o presente Acordo; b) quando a Parte requerente não tiver utilizado todos os meios disponíveis em seu próprio território para obter as informações, exceto quando o recurso a tais meios ocasionar dificuldades desproporcionais; ouc) quando a revelação das 
Além disso, observa-se que o Brasil, embora não seja membro da OCDE, vem celebrando diversos tratados para relativos à bitributação internacional e à assistência para a cobrança de impostos ${ }^{18}$, com diversos países (VALADÃO, 2015, p.383), mas a maioria deles ainda não inclui dispositivo semelhante ao contido no inciso $\mathrm{V}$ do art. 26, do modelo da Convenção da OCDE relativo à vedação da exceção de prestação de informações sob o pretexto do sigilo. (GODOY, 2015, p. 366).

A exceção se depreenderia do conteúdo do tratado celebrado com os Estados Unidos da América, supramencionado, o qual não permitiria exceções relacionadas ao sigilo, assim como consideraria que, dentre as autoridades competentes para a formulação de requisições, estariam as autoridades fazendárias.

A questão da validade com que os tratados internacionais é reconhecida no Brasil ainda constitui ponto relativamente polêmico, mas, partindo-se da premissa, considerada como correta no âmbito do presente estudo, de que os tratados que não integram o sistema internacional de reconhecimento e proteção aos direitos humanos constituam regramentos que tem valor equivalente às leis ordinárias ${ }^{19}$, a questão da constitucionalidade do acesso direto pelo fisco a dados bancários deveria também contemplar um controle de relativo à compatibilidade,

informações requeridas for contrária ao interesse público da Parte requerida.

18 Além do decreto relativo ao acordo firmado com o governo americano, o Brasil é signatário de muitos outros acordos destinados relativos à dupla tributação, troca de informações e de assistência na cobrança de impostos, a exemplo dos tratados firmados com a África do Sul, Argentina, Áustria, Bélgica, Canadá, China, República da Coreia, Dinamarca, Equador, Espanha, Filipinas, Finlândia, França, Hungria, Índia, Israel, Luxemburgo, México, Itália, Noruega, Holanda, da antiga Tchecoeslováquia (atual repúblicas tcheca e eslovaca), coma Suécia, Ucrânia e Portugal.

19 Segundo Sarlet (2013, p. 104), onde o autor refere que: “ Assim, à vista do exposto, enquanto não sobrevenha uma posição uniformizadora, ao que tudo indica, são três as possibilidades atualmente reconhecidas pelo STF: a ) a hierarquia (equivalente) de emenda constitucional, no caso dos tratados de direitos humanos incorporados mediante observância do rito estabelecido pelo $\S 3^{\circ}$ do artigo $5^{\circ}$ da CF; b) hierarquia supralegal, aplicável aos tratados de direitos humanos ratificados pelo sistema convencional, por meio de Decreto Legislativo aprovado com maioria simples; c) hierarquia de lei ordinária, que segue sendo a posição adotada em relação aos demais tratados, que não integram o sistema internacional de reconhecimento e proteção dos direitos humanos. 
ou como vêm sendo referido pela doutrina majoritária, um controle de convencionalidade ${ }^{20}$, entre o conteúdo dos tratados dos quais o Brasil é signatário e suas leis internas.

A despeito da regra geral que equipara os tratados que não se referem à direitos humanos à legislação ordinária interna, e interessante referir que, em termos de tributação, o próprio Código Tributário Nacional, no texto do art.98 21 , consagraria a primazia às normas consolidadas nos tratados. $^{22}$

Assim, torna-se possível referir o direito brasileiro interno, que contém disposições em matéria tributária esteja sujeito a um controle no que se refere à sua compatibilidade, ou a um controle de convencionalidade entre suas disposições e o direito consagrado nos tratados em matéria tributária ${ }^{23}$, devendo o regramento consagrado nos tratados ser tomados como regras que devam preponderar em caso

20 Vide Barroso (2013), que refere a necessidade de controle do conteúdo do direito nacional em relação aos tratados internacionais, segundo a teoria do monismo jurídico, que entende que o direito nacional e internacional devam formar uma unidade.

21 Segundo o art.98 do Código Tributário Nacional: "Os tratados e as convenções internacionais revogam ou modificam a legislação tributária interna, e serão observados pela que lhes sobrevenha." Ainda, pelo parágrafo único do art. 199 do Código Tributário Nacional, incluído pela LC 104/2001: “Art.199Parágrafo único. A Fazenda Pública da União, na forma estabelecida em tratados, acordos ou convênios, poderá permutar informações com Estados estrangeiros no interesse da arrecadação e da fiscalização de tributos." (BRASIL, 1966).

22 Nesse contexto, interessantes os argumentos lançados por Barroso (2013, p. 154), quando refere que: "existem algumas exceções a essa equiparação entre tratado e lei ordinária, para efeito de resolução de conflitos. A primeira dá-se em matéria relativa à tributação, onde o art.98 do Código Tributário Nacional (Lei n.5172, de 25.out.1966), como visto, é expresso quanto à prevalência da norma internacional.

23 Dada a relativa novidade da discussão do tema do controle de convencionalidade no direito brasileiro, é possível afirmar que a possibilidade de realização de controle de convencionalidade entre o direito interno e os tratados que tratam de direito comum ou de legislação tributária com caráter supralegal, por força do artigo 98 do CTN a partir da leitura do texto de Sarlet (2013, p. 113), onde refere que: "Outro tópico de relevo e que aqui se refere em caráter ilustrativo, diz com os efeitos do controle de convencionalidade sobre a normativa legal e infralegal interna. Nesse contexto, o STF já se pronunciou pelo reconhecimento do que designou (especialmente por ocasião do voto proferido pelo Ministro Gilmar Mendes, já referido) de um efeito paralisante, que impede a edição de legislação superveniente em sentido contrário e afasta a aplicação de lei anterior incompatível com o tratado. Se a exemplo do que se verifica no controle de constitucionalidade se poderá declarar a nulidade da lei com base em tratado internacional (hipótese mais plausível em se tratando de tratado com status equivalente a emenda constitucional), portanto, se é o caso de afetação da esfera da validade ou apenas da eficácia dos atos normativos aferidos com base nos tratados internacionais, constitui igualmente tópico a ser explorado pela literatura e submetido ao crivo da prática decisória dos Tribunais." 
de conflito, segundo o regramento do artigo 98 do Código Tributário Nacional.

Nesse contexto, a adesão brasileira a tratados que, em realidade permitem, portanto, o acesso às informações bancárias por autoridades fiscais, e que não admitem alegações relacionadas ao sigilo bancário como motivo de exceção, constituiria mais um forte indicativo no sentido de que a Lei Complementar n ${ }^{\circ}$ 105/2001 deva ter sua constitucionalidade reconhecida, no que se refere à possibilidade de acesso direto às informações pelo fisco, sem necessidade de intermediação judicial. Além disso, embora não aventada a questão do controle de convencionalidade da Lei Complementar $n^{\circ} 105 / 2001$, no julgamento reconhecido como de repercussão geral no Supremo Tribunal Federal, em que se discute a constitucionalidade desse dispositivo, é possível afirmar que, acaso tal controle fosse realizado, deveria se dar no sentido de que o regramento previsto na LC 105/2001 está perfeitamente de acordo com as regras estabelecidas pelo tratado internacional já referendado pelo Brasil com o governo americano em relação ao tema.

\section{CONCLUSÃO}

As questões abordadas no presente estudo permitiram que se refira que, em realidade, a Constituição não consagra o sigilo bancário como direito fundamental. Assegura, sim, o direito de proteção à vida privada e o sigilo de dados. A vida privada seria relacionada às questões da esfera íntima da pessoa, que a protege contra a intromissão indevida relacionada à curiosidade alheia. O sigilo de dados, a seu turno, seria relacionado à proteção dos processos de comunicação da pessoa, e não aos dados em si. Contudo, mesmo esses direitos protegidos não teriam 
caráter absoluto.

Assim, a proteção assegurada pela Constituição Federal teria por escopo, principalmente, questões relativas à exposição indevida da vida privada dos indivíduos, mas tal proteção teria um caráter que, em muitos casos, deve ser ponderado em relação a outros princípios.

No presente estudo, tratamos da possibilidade de acesso às informações bancárias pessoais e empresariais diretamente pelo fisco, sem necessidade de autorização judicial para tanto, conforme permissivo contido na Lei Complementar $n^{\circ} 105 / 2001$, e da consequente discussão acerca da constitucionalidade desta lei frente às disposições constitucionais que determinam a proteção da privacidade e dos processos de transmissão de dados pessoais.

Observa-se que, no caso do acesso das informações, não haveria razão para se falar em exposição da vida privada ou de dados pessoais. Isso se verifica porque, nas situações em que a administração tributária acessa diretamente os dados bancários de determinada pessoa, o faz mediante processo administrativo devidamente instaurado.

Isso ocorre porque, conforme explicitado, uma vez que a administração tributária tenha acesso a informações bancárias de determinado indivíduo, esta tem o dever de manter as referidas informações sigilosas, caracterizando-se a quebra deste dever de sigilo como crime, inclusive. O que ocorre nesses casos, em realidade, é a transferência dos dados sigilosos ao Fisco, passando-se do sigilo bancário ao sigilo fiscal, sendo mantido o sigilo que preserva essas informações e dados do conhecimento público.

Muitos argumentam no sentido da inconstitucionalidade dos dispositivos da Lei Complementar n¹05/2001, referindo que o fisco não poderia ter este acesso franqueado, considerada sua situação de 
parte interessada na cobrança dos tributos eventualmente em discussão, ou eventualmente sonegados pelo contribuinte. Contudo, ainda que não seja pacífico o entendimento no sentido de que, em realidade, com a transferência do sigilo bancário ao fisco, mantenha-se o caráter sigiloso destas informações, há que se observar que, mesmo aqueles que entendam que possa haver algum grau de lesão aos direitos de privacidade, devem avaliar a discussão realizando um juízo de ponderação entre o eventual prejuízo à privacidade frente ao ganho potencial para a sociedade.

Assim, o entendimento considerado no presente estudo como mais adequado é aquele que faria preponderar o interesse público exercido pela administração tributária, relacionado à eficiência na cobrança de tributos e às possibilidades que as previsões contidas na Lei $n^{\circ}$ 105/2001 agregam às necessidades de prevenção e combate à evasão tributária, à lavagem de dinheiro e à corrupção, entendimento este que fortalece a confiança nas possibilidades de concretização dos valores da justiça e da democracia.

O tema vem sendo debatido no judiciário brasileiro há bastante tempo, sem que se tenha chegado ainda a uma conclusão definitiva. $\mathrm{O}$ assunto teve sua repercussão geral reconhecida pelo Supremo Tribunal Federal em 2009, no julgamento do Recurso Extraordinário nº 601.314/ SP, sem que, contudo, tenha sido definitivamente julgado até o momento.

Em termos internacionais, é possível afirmar que processos proporcionados pela globalização, como o da internacionalização de capitais, de pessoas e bens, passou a gerar também inegáveis facilidades para aqueles que se valem destes mecanismos com fins ilícitos e de evasão fiscal.

Diversos organismos internacionais, como a OCDE- Organização para Cooperação e Desenvolvimento Econômico e para a ONU- 
Organização das Nações Unidas passaram a priorizar a questão da celebração de tratados de cooperação internacional para o intercâmbio de informações fiscais, que permitam, entre outras facilidades, a troca de informações e o acesso aos dados bancários e fiscais pelas autoridades fazendárias dos países comprometidos nos acordos.

Verifica-se, portanto, uma tendência transnacional relativa à celebração de tratados para a troca de informações entre Administrações Tributárias. O Brasil é signatário de diversos tratados relativos à bitributação internacional, que também preveem cláusulas relacionadas à troca de informações, além de um tratado específico sobre troca de informações tributárias celebrado com os Estados Unidos da América.

Considerando-se o entendimento no sentido de que os tratados dos quais o Brasil é signatário constituam normas de caráter legal, ou ainda, no sentido da superioridade dos tratados relativos à tributação em relação às normas nacionais, conforme previsão do art.98 do Código Tributário Nacional, é possível afirmar que existam fortes indicativos no sentido de que seja reconhecida a constitucionalidade da Lei Complementar $n^{\circ}$ $105 / 2001$, eis que o Brasil já possui em vigor o tratado celebrado com o governo americano, que prevê o acesso pelas administrações fiscais aos dados bancários e o consequente intercâmbio destas informações, que não poderiam ser exepcionadas por alegações relacionadas ao sigilo bancário, uma vez que o controle de constitucionalidade da referida norma devesse também abranger o controle de convencionalidade da legislação interna em relação ao tratado internacional do qual o Brasil é signatário.

A questão da transparência em matéria fiscal passou, portanto, a integrar um plano jurídico supranacional, de formação de mecanismos para o combate à evasão fiscal. Assim, é possível afirmar que, embora ainda pendente de julgamento no Supremo Tribunal Federal, a decisão 
mais coerente e acertada a ser tomada pelo Supremo Tribunal Federal deverá chancelar a constitucionalidade Lei Complementar $n^{\circ}$ 105/2001.

\section{REFERÊNCIAS}

ALEXY, Robert. Teoria dos direitos fundamentais. Tradução de Virgílio Afonso da Silva. São Paulo: Malheiros, 2008.

ANTUNES, Carmen Lúcia Rocha. Direito à privacidade e os sigilos fiscal e bancário. Interesse Público-IP, Belo Horizonte, ano 5, n. 20, p. 13- 43, jul./ago. 2003.

BANCO CENTRAL DO BRASIL. Lei complementar $\mathbf{n}^{0} 105$ de 10 de janeiro de 2001. Dispõe sobre o sigilo das operações de instituições financeiras e dá outras providências. Disponível em: < http://www.bcb.gov.br/pre/leisedecretos/Port/Lei_Compl105.pdf>. Acesso em: 5 mar. 2017.

BARROSO, Luis Roberto. Constituição e tratados internacionais: alguns aspectos da relação entre direito internacional e direito interno. In: MARINONI, Luiz Guilherme; MAZZUOLI, Valerio de Oliveira (Coord.). Controle de convencionalidade, um panorama latinoamericano: Brasil, Argentina, Chile, México, Peru, Uruguai. Brasília, DF: Gazeta Jurídica, 2013. p. 147-180.

\section{BRASIL. Constituição (1988). Constituição da República}

Federativa do Brasil. Disponível em: <http://www.planalto.gov.br/ ccivil_03/constituicao/constituicao.htm>. Acesso em: 6 jun. 2016.

\section{BRASIL. Decreto $\mathbf{n}^{\mathbf{0}} \mathbf{8 . 0 0 3}$, de 15 de maio de 2013. Promulga} o Acordo entre o Governo da República Federativa do Brasil e o Governo dos Estados Unidos da América para o Intercâmbio de Informações Relativas a Tributos, firmado em Brasília, em 20 de março de 2007. Disponível em: < http://www.planalto.gov.br/ ccivil_03/_ato2011-2014/2013/decreto/D8003.htm>. Acesso em: 5 
mar. 2017.

BRASIL. Lei $n^{0}$ 5.172, de 25 de outubro de 1966. Dispõe sobre o Sistema Tributário Nacional e institui normas gerais de direito tributário aplicáveis à União, Estados e Municípios. Disponível em: $<$ http://www.planalto.gov.br/ccivil_03/leis/L5172.htm>. Acesso em: 5 mar. 2017.

BRASIL. Supremo Tribunal Federal. AC 33: Tribunal Pleno, Relator: Min Marco Aurélio, julgamento em 24 nov. 2010a. Disponível em: http:/www.stf.jus.br/portal/jurisprudencia/ listarJurisprudencia. asp?s $1=\% 28 \mathrm{AC} \% 24 \% 2 \mathrm{ESCLA} \% 2 \mathrm{E}+\mathrm{E}+33 \%$ $2 \mathrm{ENUME} \% 2 \mathrm{E} \% 29+\mathrm{OU}+\% 28 \mathrm{AC} \% 2 \mathrm{EACMS} \% 2 \mathrm{E}+\mathrm{ADJ} 2$ $+33 \% 2 \mathrm{EACMS} \% 2 \mathrm{E} \% 29 \&$ base=baseAcordaos \&url=http://tinyurl. com/ajgmahd. Acesso em: 22 set. 2015.

BRASIL. Supremo Tribunal Federal. RE 601.314/SP: repercussão geral no Recurso Extraordinário. Relator Min Ricardo Lewandowski, julgamento em 22 out. 2009. Disponível em: $<$ http://www.stf.jus.br/portal/jurisprudencia/listarJurisprudencia. asp?s $1=\% 28 \mathrm{RE} \% 24 \% 2 \mathrm{ESCLA} \% 2 \mathrm{E}+\mathrm{E}+601314 \% 2 \mathrm{ENU}$ $\mathrm{ME} \% 2 \mathrm{E} \% 29+\mathrm{OU}+\% 28 \mathrm{RE} \% 2 \mathrm{EPRCR} \% 2 \mathrm{E}+\mathrm{ADJ} 2+$ 601314\%2EPRCR\%2E\%29\&base=base baseRepercussao\&url=http:// tinyurl.com/a97p879>. Acesso em: 22 set. 2015.

CAMBI, Eduardo; POMPÍLIO, Gustavo. Sigilo bancário: a visão do STF sobre o acesso direto pelo fisco sem autorização judicial. Revista AJURIS, Porto Alegre, v. 41, n. 135, p. 91-114, set. 2014.

FERRAZ JUNIOR, Tércio Sampaio. Sigilo bancário- privacidade e liberdade. In: SARAIVA FILHO, Oswaldo Othon de Pontes; GUIMARÂES, Vasco Branco (Coord.). Sigilos bancário e fiscal: homenagem ao jurista José Carlos Moreira Alves. 2. ed. Belo Horizonte: Fórum, 2015. p. 85-89. 


\section{HALIFAX, E. O. Processo C-255/02. 2006.}

Disponível em: $<\mathrm{http}: / /$ curia.europa.eu/juris/showPdf. jsf?text $=\&$ docid $=56198 \&$ pageIndex $=0 \&$ doclang $=$ pt\&mode $=$ doc\&dir $=\&$ occ $=$ first $\&$ part $=1 \&$ cid $=188371>$. Acesso em: 26 out. 2015.

GODOY, Arnaldo Sampaio de Moraes. Aviso de incêndio - sigilo fiscal e restrições do Brasil ao art. 26 da Convenção Modelo da Organização para a Cooperação e Desenvolvimento Econômico (OCDE). In: SARAIVA FILHO, Oswaldo Othon de Pontes; GUIMARÂES, Vasco Branco (Coord.). Sigilos bancário e fiscal: homenagem ao jurista José Carlos Moreira Alves. 2. ed. Belo Horizonte: Fórum, 2015. p. 365-381.

MAZÁK, J. Processo C -451/05. 2006. Disponível em: $<$ http://curia.europa.eu/juris/showPdf. jsf?text=SEGREDO \%2BBANC\%25C3\%2581RIO\&docid $=61456 \&$ pageInde $=0 \&$ doclang $=$ pt $\&$ mode $=$ req $\&$ dir $=\& o c c=$ first \&part=1\&cid=190150>. Acesso em: 26 out. 2015.

NEVES, Marcelo. Transconstitucionalismo. São Paulo: Martins Fontes, 2013.

OCDE. 2000/2005 - convenção modelo: convenção entre o (estado A) e o (estado B) em matéria de imposto sobre o rendimento e sobre o patrimônio. Disponível em: $<$ http://info.portaldasfinancas.gov.pt/ NR/rdonlyres/479C17F 1-84B8-45F8-8056-73B300425BAD/0/CDT Modelo_OCDE.pdf $>$. Acesso em: 26 set. 2015.

\section{OECD. Articles of the model convention with respect to taxes on} income and on capital. 2008. Disponível em: <http://www.oecd.org/ tax/treaties/42219418.pdf>. Acesso em: 26 set. 2015.

ROCHA, Carmen Lúcia Antunes. Direito à privacidade e os sigilos fiscal e bancário. Interesse Público, Belo Horizonte, ano 5, n. 20, p. 13-43, jul./ago. 2003. 
SANTI, Eurico Marins. O sigilo bancário e a lei tributária transparência, controle da legalidade, direito à prova e transferência do sigilo para a Administração Tributária na Constituição e na Lei Complementar $n^{\circ}$ 105. In: SARAIVA FILHO, Oswaldo Othon de Pontes; GUIMARÂES, Vasco Branco (Coord.). Sigilos bancário e fiscal: homenagem ao jurista José Carlos Moreira Alves. 2. ed. Belo Horizonte: Fórum, 2015. p. 545-593.

SARLET, Ingo Wolfgang; MOLINARO, Carlos Alberto. O direito à informação na ordem constitucional brasileira: breves apontamentos. In: SARLET, Ingo Wolfgang; MATOS, José Antonio Montilla; RUARO, Regina Linden (Coord.). Acesso à informação como direito fundamental e dever estatal. Porto Alegre: Livraria do Advogado, 2016. p. 11- 26.

SARLET, Ingo. Notas sobre as relações entre a Constituição Federal de 1988 e os Tratados Internacionais de Direitos Humanos na perspectiva do assim chamado controle de convencionalidade. In: MARINONI, Luiz Guilherme; MAZZUOLI, Valerio de Oliveira (Coord.). Controle de convencionalidade, um panorama latinoamericano: Brasil, Argentina, Chile, México, Peru, Uruguai. Brasília: Gazeta Jurídica, 2013. p. 87-116.

TORRES, Ricardo Lobo. Sigilos bancário e fiscal. In: SARAIVA FILHO, Oswaldo Othon de Pontes; GUIMARÂES, Vasco Branco (Coord.). Sigilos bancário e fiscal: homenagem ao jurista José Carlos Moreira Alves. 2. ed. Belo Horizonte: Fórum, 2015. p. 127-138.

UNITED NATIONS. Model double taxation convention between developed and developing coutries. New York: UN, 2001. p. 4344. Disponível em: <http://www.un.org/esa/ffd/documents/UN_ Model_2011_Update.pdf>. Acesso em: 26 nov. 2015.

VALADÃO, Marcos Aurélio Pereira. Troca de informações com base em tratados internacionais e os sigilos fiscal e bancário. In: SARAIVA 
FILHO, Oswaldo Othon de Pontes; GUIMARÂES, Vasco Branco (Coord). Sigilos bancário e fiscal: homenagem ao jurista José Carlos Moreira Alves. 2. ed. Belo Horizonte: Fórum, 2015. p. 383-409.

Como citar: LAKS. Larissa Rodrigues. Liberdade de informação e privacidade: o debate sobre a constitucionalidade da transferência do sigilo bancário à administração tributária. Revista do Direito Público, Londrina, v. 12, n. 1, p.86-118, abr. 2017. DOI: 10.5433/24184-108181-1X.2017v12n1p86. ISSN: 1980-511X.

Recebido em: 08/02/2016

Aprovado em: 23/11/2016 